\title{
Универсальный температурный режим инкубации яиц мясных кроссов кур для приусадебного и фермерского птицеводства
}

Судаков А.Н., аспирант кафедры технологического оборудования, процессов перерабатывающих производств, механизации сельского хозяйства и безопасности жизнедеятельности

Андрианов Е.А., доктор сельскохозяйственных наук, профессор, доцент кафедры технологического оборудования, процессов перерабатывающих производств, механизации сельского хозяйства и безопасности жизнедеятельности ФГБОУ ВО «Воронежский государственный аграрный университет имени императора Петра \» (Воронежский ГАУ) Скользнев Н.я., кандидат биологических наук, директор заповедника кГаличья гора» ФГБОУ вО «Воронежский государственный университет» (ВГУ)

Аннотация: Цель работы - разработать униберсальный температурный режим инкубации яиц мясных кроссов кур, доступный для приусадебных и фермерских хозяйств, основанный на параметрах естественного насиживания и позболяющий повысить выбодимость яиц при использовании бытовых и полупрофессиональных инкубаторов. Объектом исследования были инкубационные яйца кур кросса «Кобб500». Изучали параметры естественного насиживания под наседками породы бентамка. Установили, что характерной особенностью естественного насижибания являются краткосрочные охлаждения яии, синхронизированные по бремени с поворотами. Средняя кратность охлахдений под наседкой составляет 2,9 раза 6 час, а средняя продолжительность одного охлаждения - 129 сек. На основании параметров естестөенного насиживания осущестөили расчет температурного режима искусственной инкубации $с$ учетом компенсации охлаждений. Приводятся материалы по разработке устройства для реализации предлагаемого режима инкубации. В результате сравнительных экспериментов по применению разработанного режима инкубации установлен рост вы6ода иыплят с 40\% 6 контроле до 67\% - 6 6ытовом инкубаторе, и с 79\% 6 контроле до 86\% - 8 полупрофессиональном инкубаторе. Отмечена тенденция к повышению сохранности и показателей скорости роста молодняка 6 опытных партиях. Ключебые слоба: мясные куры, яйца, инкубатор, температура, охлаждение, выводимость яиц.

Введение. Промышленное птицеводство является крупнейшим источником животного белка для населения Российской Федерации и, по сравнению с другими секторами мясного животноводства, развивается наиболее высокими темпами. С каждым годом отмечается рост потребления мяса птицы, как в процентах относительно свинины и мяса крупного рогатого скота, так и в абсолютном значении [1]. Следует отметить, что на сегодняшний день в мясном промышленном птицеводстве преобладают зарубежные кроссы. Учитывая, что птицеводство играет важную роль в обеспечении продовольственной безопасности страны, зависимость от зарубежных производителей вызывает обоснованную тревогу российских ученых, которые ведут работу, направленную на создание отечественных мясных кроссов. Объективной сложностью является недостаток опытных хозяйств, что в значительной степени замедляет работы в области селекции.

Вместе с тем, помимо промышленного птицеводства, в России существует категория птицеводов, 
стоящих особняком - это приусадебные и фермерские хозяйства [2]. Испокон веков содержание птицы на русском подворье являлось как продовольственной поддержкой сельского жителя, так и эстетической составляющей русской деревни.

Несмотря на растущую урбанизацию, все большее количество горожан стремится в летний период выехать за город, и в ряде случаев в этот период заводят сельскохозяйственных животных. События последних месяцев, связанные с пандемией короновирусной инфекции и необходимостью самоизоляции, вызвали взрывной рост интереса горожан к переезду в сельскую местность; следовательно, можно предположить, что интерес к приусадебному и фермерскому птицеводству в ближайшее время будет расти.

Учитывая, что приусадебное и фермерское птицеводство не сконцентрированы на краткосрочной финансовой прибыли, а имеют значительно более широкие интересы, такие как получение экологически чистой продукции, хобби, полезные физические нагрузки и воспитание подрастающего поколения, именно малые формы птицеводства могут являться перспективным направлением для первичного тестирования новых российских мясных кроссов.

Вместе с тем, наряду с высоки- ми показателями продуктивности, следствием селекционной работы являются повышенные требования современных мясных кроссов ко всем этапам процесса выращивания, первым из которых является искусственная инкубация яиц [3].

Несмотря на широкий ассортимент доступных по цене инкубаторов и высокие нормируемые показатели выводимости мясных кроссов при промышленной инкубации, показатели выводимости в подсобных хозяйствах зачастую значительно ниже.

Можно выделить три основных негативных фактора, вызывающих снижение показателей выводимости в небольших птицеводческих хозяйствах. Географическая удаленность ряда хозяйств является причиной несоблюдения условий хранения и транспортировки инкубационных яиц. Большинство доступных инкубаторов не обеспечивают требуемую точность поддержания температурно-влажностного режима. Выполнение рекомендаций производителя яиц по поддержанию значений температуры воздуха в камере инкубатора на основе данных о температуре скорлупы яиц требует определенных навыков, оборудования, временных затрат, однако, даже при желании, птицевод далеко не всегда может реализовать полноценное контактное измерение температу- ры скорлупы яиц [4]. На сегодняшний день установлено, что максимальные значения выводимости обеспечиваются при поддержании температуры скорлупы яиц кур $37,8^{\circ} \mathrm{C}$ [5].

В комплексе перечисленные выше факторы могут оказывать значительное влияние на показатели выводимости яиц и качества молодняка.

Учитывая, что личный позитивный опыт искусственной инкубации играет важную роль в отношении к кроссу или породе в целом, а перечисленные выше негативные факторы имеют обьективный характер и в ряде случаев неизбежны, возможным решением проблемы низкой выводимости яиц кур мясных кроссов в малых птицеводческих хозяйствах является поиск принципиально иного режима инкубации, предьявляющего минимальные требования к качеству инкубатора и подготовке обслуживающего его человека.

В основе исследования лежит общеизвестный факт, что в процессе естественного насиживания яйца подвергаются значительным колебаниям температуры, при этом показатели выводимости яиц под наседкой стабильно высокие, а качество молодняка выше, чем при искусственной инкубации [6]. В ходе предварительных экспериментов было также установлено, что наседки породы бентамка с успехом выводят яйца кросса 
Ko66-500.

С учетом изложенного выше была определена цель исследования - разработать универсальный температурный режим искусственной инкубации на основе параметров естественного насиживания. Для достижения поставленной цели были решены следующие задачи: осуществить мониторинг параметров естественного насиживания современными техническими средствами, на основе полученных данных математически рассчитать новый режим инкубации, разработать устройство для реализации полученного режима и осуществить контрольную инкубацию яиц.

\section{Материал и методика} исследований. Исследование проводили в 2019 г. в лаборатории на базе инкубатория заповедника «Галичья гора» ВГУ по адресу: Российская Федерация, Липецкая область, Задонский район, село Донское.

Контроль параметров естественного насиживания осуществляли под тремя наседками породы бентамка на яйцах кросса Ко66-500 при помощи лабораторного комплекса технического контроля инкубации собственной разработки (рис. 1) [7].

Математический расчет нового режима инкубации осуществлялся на основании усредненных значений параметров естественного насиживания.

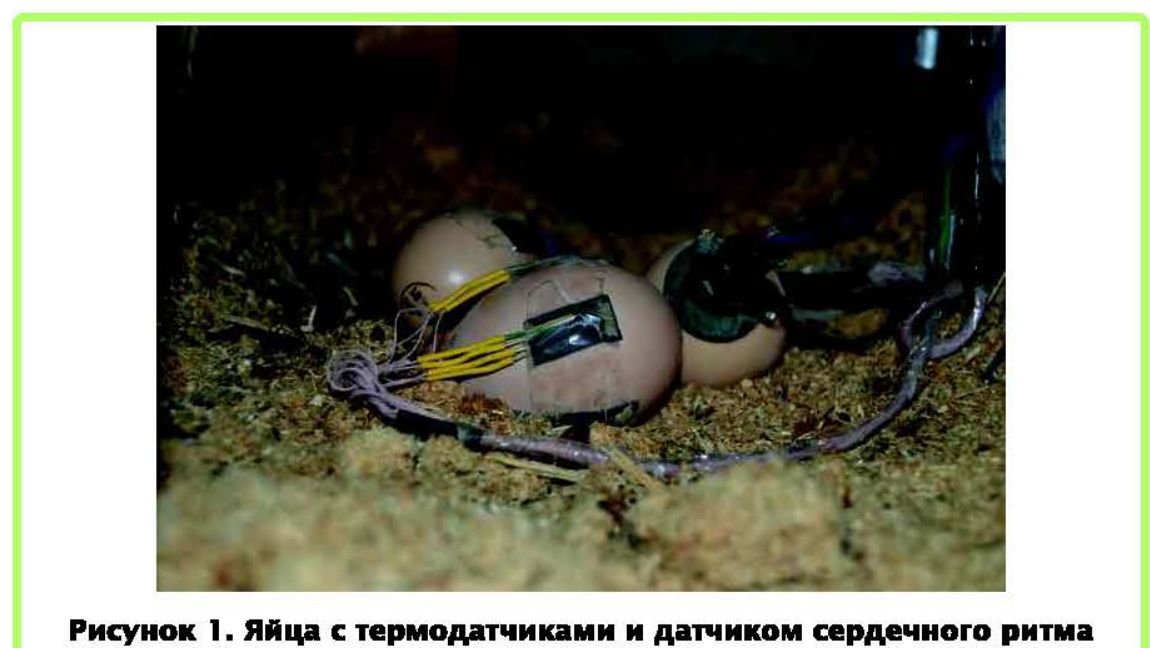

Рисунок 1. Яйца с термодатчиками и датчиком сердечного ритма

Устройство для реализации разработанного режима инкубации, предполагающего краткосрочные, синхронизированные с поворотом, охлаждения, разрабатывали с учетом общедоступной элементной базы и возможности применения на большинстве типов инкубаторов.

Для проверки разработанного режима инкубации и оборудования для его осуществления было проведено два опыта по инкубации яиц кросса Коб6-500 в различных типах инкубаторов. В бытовых инкубаторах производства КНР (I36) инкубировали 2 партии по 30 яиц, в полупрофессиональных инкубаторах Рэмил-1000 инкубировали 2 партии по 150 яиц.

Результаты инкубации и полученный молодняк оценивали по зоотехническим показателям, доступным для контроля в малых птицеводческих хозяйствах.

Результаты исследований и их обсуждение. Контроль иараметроб естестбенного насижисания. В результате инструмен- тального контроля параметров естественного насиживания было установлено несколько характерных особенностей температурного режима яиц под наседкой:

1. Содержимое яиц под наседкой имеет температурный градиент, обусловленный разницей температур тела наседки и подстилки гнезда. Учитывая, что в ряде случаев показатель градиента имеет малые значения, а реализация контактного нагрева в бытовых инкубаторах является сложной технической задачей, было принято решение не учитывать температурный градиент яйца при разработке нового режима.

2. Температура скорлупы яйца под наседкой нестабильна. Данный факт подтверждается отсутствием горизонтальных участков на термограммме после ранжирования средней температуры скорлупы по значению (рис. 2).

При искусственной инкубации непрерывное изменение температуры воздуха обусловлено значением гистерезиса инкубатора, 


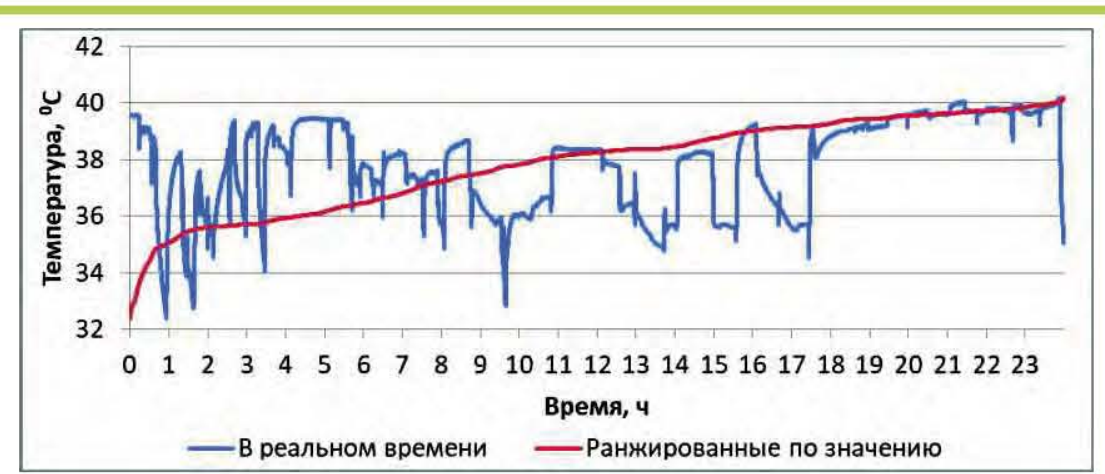

Рисунок 2. Значения температуры скорлупы

который в недорогих моделях может достигать $1^{\circ} \mathrm{C}$ и более.

3. В процессе насиживания наседка регулярно перемещает яйца в гнезде, а также периодически привстает над кладкой, при этом температура яиц снижается (табл. 1).

4. Мониторинг частоты сердечных сокращений (ЧСС) эмбриона позволил установить, что, несмотря на колебания температуры скорлупы яиц в процессе естественного насиживания, истинная средняя температура эмбриона стабильна на протяжении всего эмбриогенеза, а краткосрочные охлаждения яйца влияют на температуру скорлупы в значительно большей степени, чем на температуру эмбриона [8] (рис. 3).

5. Длительные охлаждения яиц, вызванные уходом наседки для кормления, имеют продолжительность от 10 до 50 минут и не являются обязательными, в ряде случаев наседки не покидали гнезда более суток.

Расчем темиературного рехима инкубаиии на осносанuи napamempos ecmecmoen- тем, регулярные охлаждения при отсутствии корректировки настроек температуры инкубатора для термостабильного режима не могут обеспечить требуемой для полноценного эмбрионального развития суммы температур. Учитывая приведенные выше факторы, расчет нового температурного режима осуществлялся посредством создания обобщенного уравнения суммы температур инкубации, в котором в качестве константы использовалась доказанная оптимальная температура термостабильного режима, равная $37,8^{\circ} \mathrm{C}$.

В качестве основы была принята условная схема изменений температурного режима (рис. 4).

На временном отрезке $A B$ в камере инкубатора поддерживается стабильная температура, на отрезке ВС воздух охлаждается, CD - период нагрева воздуха до исходного значения. Для сохранения требуемой для полноценного моконтрастных режимов. Вместе с

\begin{tabular}{lc} 
Tаблица 1. Средние значения параметров естественного насиживания \\
Параметр & Среднее значение \\
\hline Кратность охлаждений, -1 $^{-1}$ & 2,9 \\
\hline Длительность охлаждений, с & 129 \\
\hline Кратность поворотов, ч-1 & 2,2 \\
\hline
\end{tabular}

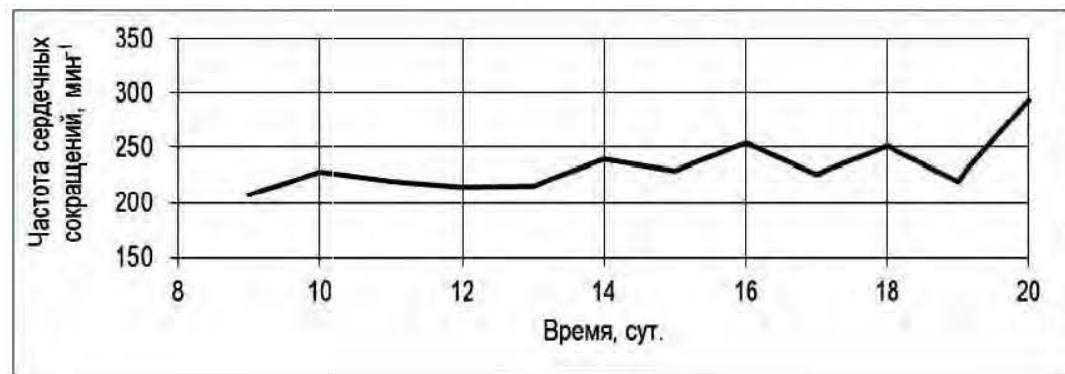

Рисунок 3. Среднее значение ЧСС эмбриона с 9-го дня насиживания 
развития эмбриона суммы температур значение температуры на отрезке AB должно быть установлено с учетом продолжительности и кратности охлаждений, а также не превышать значений, опасных для зародыша.

Общее уравнение расчета температуры инкубации было получено в результате регрессионного анализа графиков изменения температуры в процессе естественного насиживания (рис. 5). Графическая реализация общего уравнения расчета температурного режима инкубации в зависимости от продолжительности и кратности охлаждений представлена на рис. 6.

Численная реализация общего уравнения режима инкубации может осуществляться как по произвольным значениям, так и с использованием в качестве переменных средних значений кратности и продолжительности охлаждений под наседкой.

\section{Разработка устройсmбa} для реализации краткосрочных охлаждений яиц 6 камере инкубатора. Наиболее эффективным и доступным, с точки зрения технической реализации, способом краткосрочных охлаждений яиц в инкубаторе является принудительная вентиляция внутреннего объема инкубатора воздухом из помещения, в котором установлен инкубатор. Синхронизация включения вентиляторов

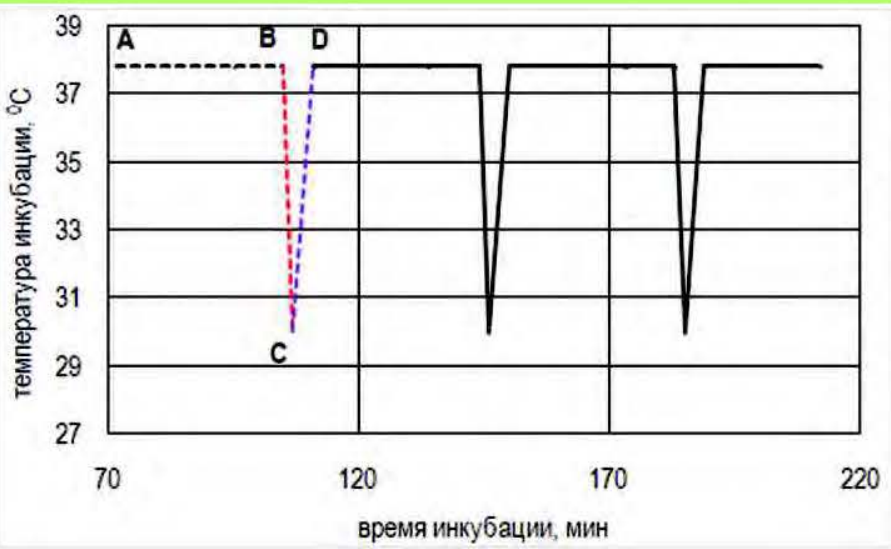

Рисунок 4. Схема изменений температуры в процессе инкубации

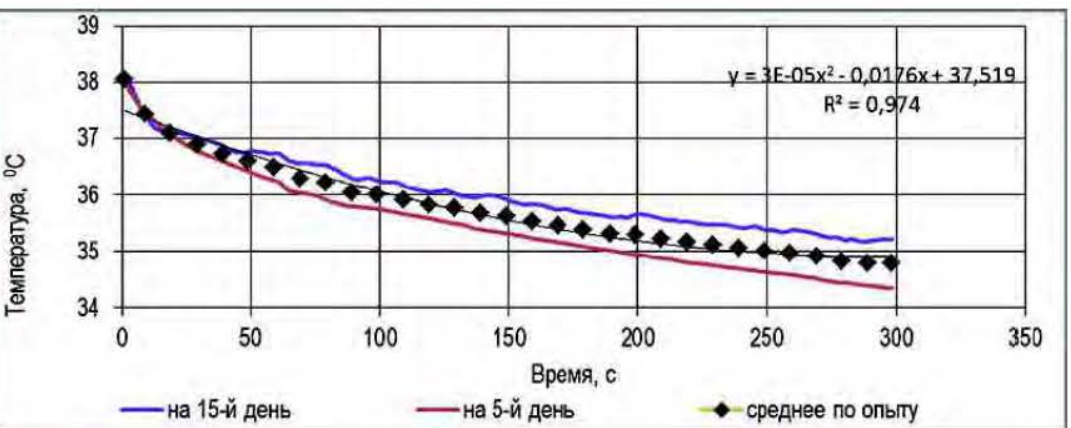

Рисунок 5. Пример графика снижения температуры скорлупы яиц на 5 и 15 дни змбриогенеза вследствие двигательной активности наседки

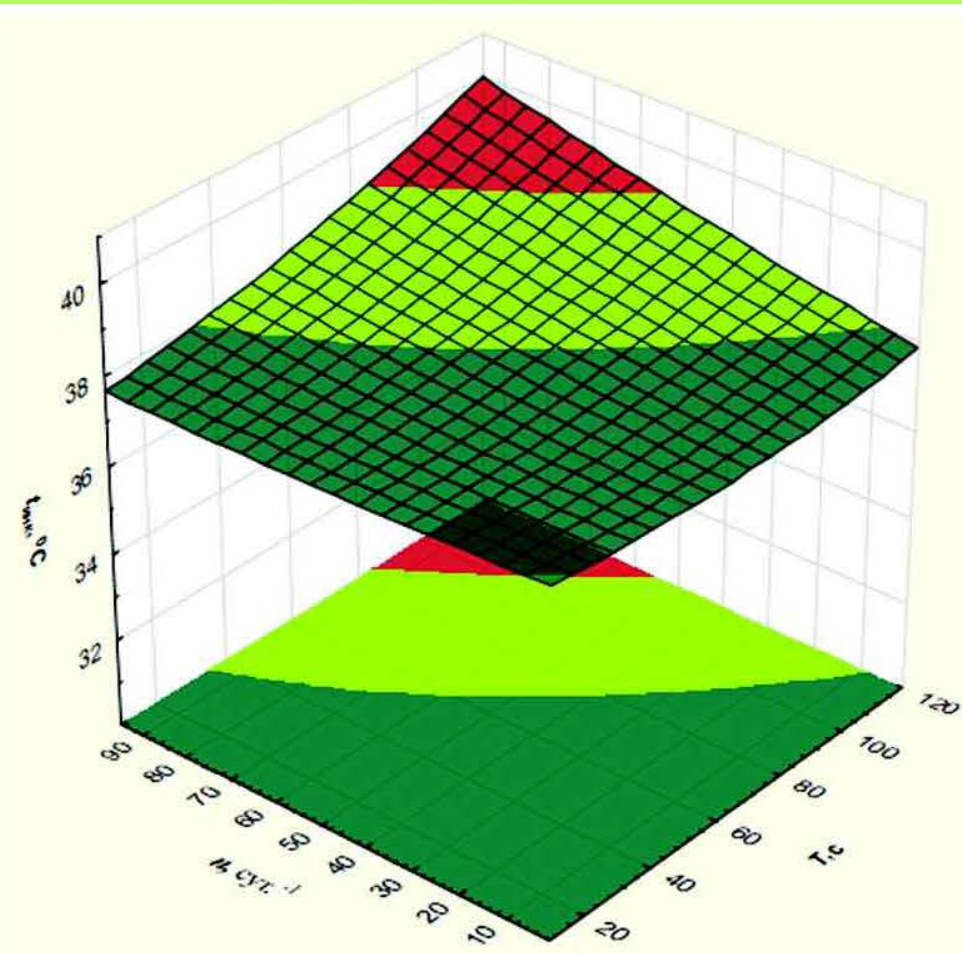

Рисунок 6. Трехмерная графическая зависимость, характеризующая искомую температуру инкубации в зависимости от длительности охлаждения и количества охлаждений в сутки при рекомендованной для данного вида птицы температуре инкубации при термостабильном режиме $t=37,8^{\circ} \mathrm{C}$ 
охлаждения с включением механизма поворота яиц может осуществляться при помощи реле времени и электромагнитных реле, управляющая цепь которых питается от контактов электродвигателя привода поворота яиц. Учитывая, что решающее значение играет сам факт охлаждения яиц, а не продолжительность воздействия, которая при естественном насиживании составляет от 10 до 300 секунд, подбор вентилятора осуществляется по формуле: $\mathrm{Q}_{\text {вент }}=\mathrm{V}_{\text {инк }} / \mathrm{T}$, где $\mathrm{Q}_{\text {вент }}-$ производительность вентилятора, м 3 /мин, Уинк - внутренний объем инкубатора, м $^{3}$, Т - длительность работы вентилятора, сек. Значение длительности работы вентилятора используется при расчете температуры инкубации.

\section{Сравнительные опыты по}

инкубации. Расчет режима инкубации был осуществлен с использованием средних значений кратности охлаждений и поворотов, а также длительности охлаждений, полученных в результате инструментального контроля параметров естественного насиживания (табл. 2).

В сравнительном опыте по инкубации яиц родительского стада кросса Коб6-500 в бытовом инкубаторе I-36 (КНР) были получены результаты, представленные в табл. 3.

В сравнительном опыте по инкубации яиц родительского стада кросса Ко66-500 в полупро-

Таблица 2. Расчепный рехким настроек инкубатора

Установлениая Установлениа Количество Количество \% сут.-1

Контрольная партия 37,8

Опытная партия 38,0 55 0 48

Таблица 3. Результаты инкубации и зоотехнические показатели молодняке при инкубации в инкубаторе I-36 Показатель Контрольная партия Опытная партия

Заложено яиц в инкубатор, шт.

Вывод цыплят, \%

Сохранность молодняка на 31 день, \%

Средняя масса бройлера на 11 день, г 30

67 67

Средняя масса бройлера на 31 день, г

$352 \pm 17,4$

$2243 \pm 69,1$ $363 \pm 10,8$ $2272 \pm 54,9$

фессиональном инкубаторе Рэмил 1000 (Россия) были получены результаты, представленные в табл. 4.

Представленные показатели вывода и последующего роста молодняка демонстрируют значительное превосходство разработанного режима инкубации при использовании бытовых инкубаторов, параметры микроклимата которых подвержены значительным колебаниям. При использовании полупрофессиональных инкубаторов разница в выводе сокращается, однако сохраняются более высокие результаты для режима инкубации, предполагающего краткосрочные охлаждения, синхронизированные с поворотом лотков.

Показатели последующего роста и сохранности молодняка не имеют значительных отличий для режимов инкубации, примененных в опытах, однако можно отметить тенденцию к увеличению жизнеспособности и скорости роста живой массы молодняка в опытных группах.

Заключение. Применение режима инкубации, включающего краткосрочные, синхронизированные с поворотом яиц охлаждения, позволяет повысить выводимость яиц при использовании бытовых и полупрофессиональных инкубаторов и компенсировать повышенную эмбриональную смертность, вызванную отклонениями от рекомендованного режима инкубации. Учитывая значительное сходство разработанного режима с температурными параметрами естественного насиживания, тенденция к росту показателей скорости роста и сохранности молодняка может

Таблица 4. Результаты инкубации и зоотехнические показатели молодняка при инкубации в инкубаторе Рэмил 1000

Показатель

Контрольная партия Опытная партия

Заложено яиц в инкубатор, шт. 150

Вывод цыплят, \%

Сохранность молодняка на $\mathbf{4 0}$ день, \%

93
86

Средняя масса бройлера на 11 день, г Средняя масса бройлера на 40 день, г
$277 \pm 4,9$

$2457 \pm 39,5$
$289+5,3$

$2570 \pm 38,2$ 
объясняться повышенной адаптационной способностью вследствие наличия колебаний температуры в процессе эмбриогенеза. Разработанный режим инкубации позволяет избежать уменьшения суммы температур, вызванных охлаждениями, а также не требует участия человека на всем протяжении инкубации.

\section{Литература}

1. Фисинин В.И. Промышленное птицеводство / В.И. Фисинин [и др.]. - М., 2016. - $534 \mathrm{c}$.

2. Бессарабов Б.Ф. Фермерское и приусадебное птицеводство / Б.Ф. Бессарабов [и др.]. - М.: ЗооВетКнига, 2015. - 265 С.

3. Щербатов В.И. Режимы инкубации и мясная продуктивность цыплятбройлеров / В.И. Щербатов, В.X. Вороков, Ю.Ю. Петренко // Птицеводство. 2015. - №1 . - C. 17-22.
4. Бурьян М. Управление температурой инкубации [Электронный ресурс] // URL:https://www.pasreform.com/ru/k nowledge/46/upravlenie-temperaturoiinkubatsii) (дата обращения 22.05.2020).

5. Joseph $\mathbf{N}$. The effects of suboptimal eggshell temperature during incubation on broiler chick quality, live performance, and further processing yield / N. Joseph, A. Lourens, E. Moran // Poult. Sci. - 2006. - V. 85. - P. 932-938.

6. Борисов В.В. Методика изучения насиживания и инкубации у птиц при помощи инструментальных методов: учеб. пособие. - Псков: Псковский гос. педаг. ун-т им. С.М. Кирова, 2006. - 52 С.

7. Andrianov E.A. The study of the natural chicken brooding in laboratory conditions / E.A. Andrianov, A.A. Andrianov, A.N. Sudakov, P.I. Dudin // IOP Conf. Series, Earth and
Environmental Science: Proc. 6th Intl. Conf. on Agriproducts Processing and Farming. - Voronezh: IOP Publishing. 2020. - V. 422. - Article ID 012051 1. doi: $10.1088 / 1755-1315 / 422 / 1 / 01205$

8. Судаков А.Н. Мониторинг температуры эмбриона птиц посредством неинвазивного контроля частоты сердечных сокращений / А.Н. Судаков, Е.А. Андрианов, А.А. Андрианов, Н.Я. Скользнев // Производство и переработка сельскохозяйственной продукции: менеджмент качества и безопасности; Мат. междунар. науч.-практ. конф. Воронеж, 2018. -Ч. 1. - С. 54-60.

\section{Для контакта с авторами:}

Судаков Александр Николаевич

E-mail: ansudak@gmail.com

Андрианов Евгений Александрович

E-mall: evgenly377@gmall.com

Скользнев Николай Яковлевич

e-mail: skolznik@mail.ru

\section{The Universal Temperature Regime for Incubation of Eggs of Broiler Breeders at Homesteads and}

Small Farms

Sudakov A.N. ${ }^{1}$, Andrianov E.A. ${ }^{1}$, Skolznev N.Ya. ${ }^{2}$

'Voronezh State Agrarian University named after Emperor Peter the Great; ${ }^{2}$ Voronezh State University

Summary: The study was aimed at the development of a universal temperature regime for incubation of eggs of broiler breeders based on the parameters of natural brooding, suitable for household and semiprofessional incubators available for homesteads and small farms, and improving egg hatchability. The study was performed on Cobb-500 eggs; natural brooding was studied with Bantam hens. It was found that natural brooding involves short periods of cooling of eggs synchronized with the turns of the eggs. The average frequency of these cooling periods is 2.9 times per hour, average duration of cooling periods 129 seconds. On the basis of these parameters the temperature regime for artificial incubation was calculated to compensate for these cooling periods. The design of the device for the realization of this regime is described. The comparative experiments revealed that hatch of chicks with this regime increased from $40 \%$ in control to $67 \%$ in the case of household incubators and from 79 to $86 \%$ in the case of semiprofessional incubators. The trends of the improvement of chick livability and growth rate were also found with this regime.

Key words: broiler chicken, eggs, incubator, temperature, cooling, hatchability of eggs. 